\title{
Sistem Penilaian Kinerja Agroindustri Teh Kebun Bantaran PT Perkebunan Nusantara
} XII

\section{Performance Measurement System Of Tea Agroindustry Bantaran Plantation Of Perkebunan Nusantara XII}

\author{
Aulia Brilliantina ${ }^{\# 1}$, Bambang Herry Purnomo*, I.B. Suryaningrat \\ ${ }^{\#}$ Mahasiswa Prodi Magister Teknologi Agroindustri, Fakultas Teknologi Pertanian, Universitas Jember \\ * Staf Pengajar Prodi Magister Teknologi Agroindustri, Fakultas Teknologi Pertanian, Universitas Jember \\ Jl. Kalimantan No. 37 Kampus Tegalboto Jember 68121, Indonesia \\ ${ }^{1}$ E-mail : Brillianthq@gmail.com
}

\begin{abstract}
Corporate performance can be measured financially and non-financially. Non-financial measurements cannot be separated from the financial measurements. The aims of this study was to describe of how performance measurement systems that has been conducted at tea agroindustry on Kebun Bantaran PT Perkebunan Nusantara XII to achieve success areas of tea agroindustry. The system was built to adopt from Integrated Dynamic Performance Measurement Systems (IDPMS) model. Interviews, observations, and company's documents were conducted to gather empirical information regarding the needs of developing new appraisal system. Four integrated functional area of the models are corporate management, factory management, production line, and lab QC. Each functional areas were linked through the specification, reporting, and dynamic updating of the defined areas of success, performance measure, and performance standard. Understanding interrelatioships of performance measurements provides the foundation for more focused improvement effort.
\end{abstract}

Keywords: Tea Agroindustry, IDPMS, Performance Measurement

\section{PENDAhUluan}

Dalam perekonomian Indonesia, teh merupakan salah satu komoditas yang mempunyai peranan cukup strategis, baik sebagai penghasil devisa negara maupun sebagai sumber pendapatan jutaan petani dan tenaga kerja. Namun, kinerja dan peran komoditas teh dalam perekonomian nasional sejak tahun 2000 cenderung menurun. Total areal kebun teh menurun 1,7\%/tahun (Indonesia Tea Board, 2015). Demikian juga produksi teh Indonesia menurun 2,3\%/tahun, lebih tinggi daripada penurunan areal tanaman teh. Sejalan dengan penurunan produksi teh tersebut, volume ekspor juga menurun, yang mengakibatkan pangsa pasar teh Indonesia di dunia menurun cukup nyata, yaitu dari 7,9\% menjadi $6,1 \%$ (BPS, 2015). Oleh karena itu perbaikan kinerja secara menyeluruh perlu dilakukan agar agroindustri teh dapat meningkatkan perannya dalam perekonomian Indonesia.

Tantangan perbaikan kinerja agroindustri teh untuk meningkatkan produksi teh dan meningkatkan mutu teh yang dihasilkan memang cukup berat mengingat terjadinya penurunan areal tanaman teh, serta terjadinya perubahan iklim di Indonesia yang menyebabkan terjadinya penurunan mutu teh yang dihasilkan. Namun bukan berarti perbaikan kinerja agroindustri teh tidak bisa dilakukan dengan ketersediaan sumberdaya yang dimiliki agroindustri teh saat ini. Berdasarkan wawancara penulis dengan manajemen agroindustri teh, diketahui bahwa agroindustri teh Kebun Bantaran dapat meningkatkan rendemennya dari 20-22\% menjadi 24-25\%. Kinerja rendemen agroindustri teh dari tahun 2012 hingga 2016 dapat dilihat pada Gambar 1. 
Aulia Brilliantina, Bambang Herry Purnomo, I.B. Suryaningrat. Sistem Penilaian Kinerja Agroindustri Teh Kebun Bantaran PT Perkebunan Nusantara XII

Pencapaian nilai rendemen teh sebagai acuan prestasi agroindustri teh harus didukung dengan penerapan manajemen kinerja yang baik dan berkelanjutan. Penerapan manajemen kinerja yang baik diharapkan dapat meningkatkan kinerja dalam rangka meningkatkan produksi teh saat ini dan menekan biaya produksi yang masih cukup tinggi, sesuai dengan ketersediaan sumberdaya saat ini. Sistem penilaian kinerja bersifat dinamik sebagai praktek manajemen kinerja menjadi solusi guna memantau perilaku dan tujuan proses bisnis agroindustri teh dari waktu ke waktu, sehingga dapat terkendali semua ukuran kesuksesan kinerja agroindustriteh. Tulisan ini merupakan bagian awal dari kajian pengembangan model sistem dinamik kinerja agroindustri teh Kebun Bantaran. Tujuan dari penellitian ini adalah mendapatkan gambaran bagaimana sistem penilaian kinerja di agroindustri teh Kebun Bantaran, sehingga dapat mencapai tingkat efisiensi yang optimal.

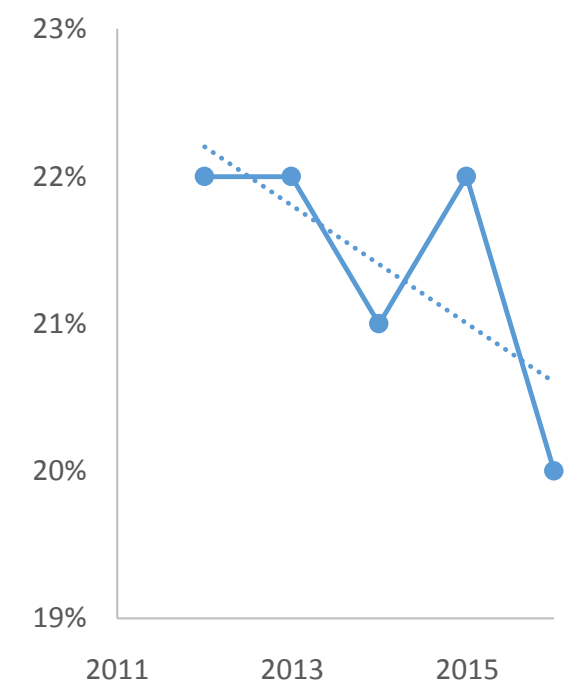

GAMBAR 1. KINERJA RENDEMEN TEH AGROINDUSTRI TEH KEBUN BANTARAN

\section{METODE PENELITIAN}

\section{Kerangka Pemikiran}

Kinerja pada agroindustri teh merupakan keterkaitan antar seluruh bagian dalam agroindustri teh tersebut. Kerjasama antara semua bagian menjadi kunci keberhasilan dalam meningkatkan kinerja agroindustri teh yang tercermin dari kinerja rendemen teh yang dihasilkan. Pencapaian kinerja rendemen teh menjadi sumber pemicu kinerja keuangan yang tercermin dari perolehan nilai keuntungan. Dalam konteks agroindustri teh, rendemen teh mutu ekspor merupakan prestasi kerja seluruh karyawan bagian tanaman, teknik dan pengolahan, serta dukungan bagian akuntansi dan umum. Keterkaitan ukuran kinerja antar bagian saling mempengaruhi ukuran kinerja bagian lainnya yang diterjemahkan dari area kesuksesan bersama manajemen agroindustri teh.

Secara tradisional, pengukuran kinerja umumnya menilai dari sisi keuangan. Pendekatan ini telah banyak ditinggal para praktisi sejak tahun 1980-an (Ghalayani, et al., 1997; Kaplan dan Norton, 1996; Busi, et al., 2006). Ketidakpuasan para praktisi melahirkan model pengukuran kinerja kontemporer. Diantaranya yaitu SMARTpyramid (Cross and Lynch, 1989), Balanced scorecard (Kaplan dan Norton, 1992), IDPMS (Integrated Dynamic Performance Measurement System) dll.

Pengembangan model sistem penilaian kinerja multi dimensi dalam studi ini merujuk model IDPMS. Penggunaan model IDPMS memungkinkan pemodel dapat menstrukturisasi sistem sesuai keadaan bagian-bagian di agroindustri teh yang telah menerapkan sistem kinerja tersebut tanpa harus memaksakan untuk memasukkan perspektif kinerja yang kurang diperlukan di agroindustri teh tersebut.

\section{Tata Pelaksanaan}

Penelitian deskripsi kinerja pada agroindustri teh ini bersifat studi kasus yang dilaksanakan di Kebun Bantaran PT Perkebunan Nusantara XII pada bulan Agustus sampai Desember 2016.Penelitian studi kasus adalah penelitian tentang status subyek penelitian yang berkenaan dengan suatu fase spesifik atau khas dan keseluruhan personalitas. Tujuannya untuk memberi gambaran secara mendetail tentang latar belakang, sifat-sifat serta karakter-karakter yang khas dari kasus, yang kemudian dari sifat-sifat yang khas itu akan dijadikan suatu yang bersifat umum (Nazir, 1999). Penelitian ini dilakukan dengan beberapa tahapan. Adapun tahapan yang dilalui yaitu tahap studi pendahuluan, pengumpulan data, dan merancang model kinerja agroindustri teh seperti dapat dilihat pada Gambar 2.

Tahap studi pendahuluan meliputi kegiatan menentukan tujuan dan lingkup penelitian. Tahap selanjutnya adalah pengumpulan data yang meliputi data primer, data sekunder serta studi pustaka tentang penilaian kinerja agroindustri teh. Data tentang kinerja agroindustri teh terutama aspek tanaman, teknik dan pengolahan, keuangan dan umum,dikumpulkan langsung dari data RKAP agroindustri teh Kebun Bantaran PTPN XII serta hasil wawancara dengan Manajer Kebun serta para pekerja di agroindutri teh Kebun Bantaran PTPN XII. 


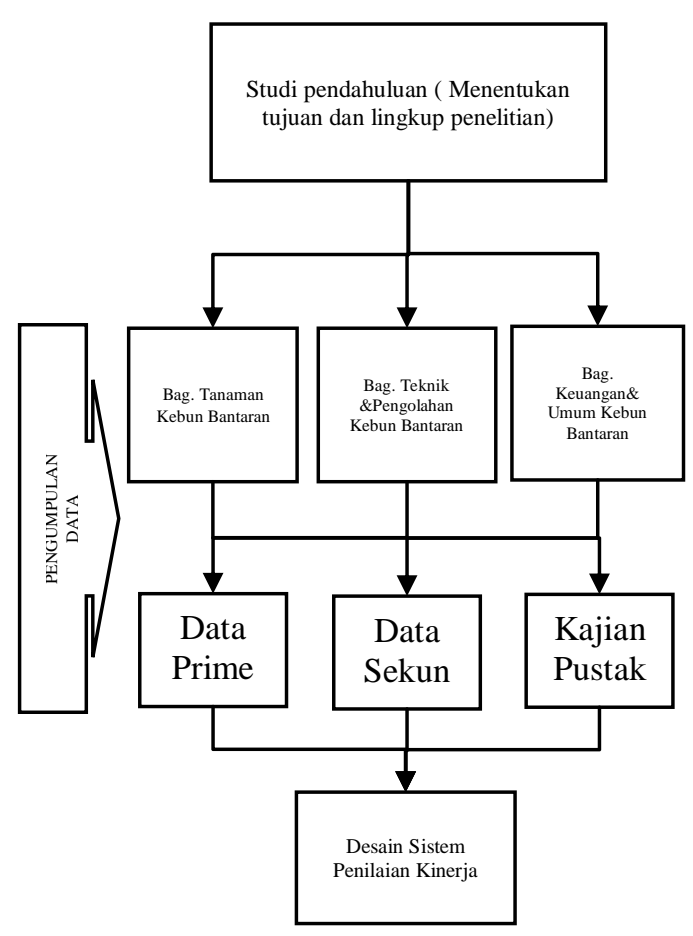

Gambar 2. Diagram Alir Penelitian

Data yang dikumpulkan pada penelitian ini terdiri data primer dan data sekunder. Data primer diperoleh dari observasi lapang, dan wawancara dengan pihak karyawan agroindustri teh Kebun Bantaran terutama dengan Manager Kebun, Asisten Kepala, Kepala Akuntansi dan Umum, Kepala Teknik dan Pabrikasi. Data sekunder diperoleh dari studi pustaka dalam rangka memperoleh landasan teoritis dan data penunjang yang berkaitan dengan materi penelitian.

Observasi lapang dilakukan pada afdeling-afdeling dan juga pabrik yang ada di agroindustri teh Kebun Bantaran, yaitu afdeling Sirah Kencong, Bantaran, dan Penataran. Penggalian informasi dari para karyawan yang bekerja di agroindutri teh Kebun Bantaran dilakukan dengan wawancara. Wawancara dilakukan pada tahap awal penelitian untuk menggali lebih dalam tentang permasalahan yang dihadapi oleh agroindustri teh Kebun Bantaran dalam sistem, menggali kebutuhan dan menjelaskan faktor-faktor yang berpengaruh. Wawancara dilakukan dengan menggunakan pertanyaan terarah.

Data dan informasi yang yang didapat pada proses identifikasi dalam perusahaan, dikonfirmasikan kepada pihak agroindustri teh Kebun Bantaran yang kemudian digunakan sebagai bahan analisis indikator pengukuran kinerja. Analisis data dengan cara mengelompokan data sesuai dengan tema kesuksesan penilaian kinerja yang hendak dicapai pada masing-masing bagian. Secara visual pengelompokan per tema menggunakan bagan struktur hirarki. Bagan struktur hirarki dapat membantu dalam menstrukturisasi ukuran-ukuran kinerja dan dapat bermanfaat secara bersama untuk pembentukan dasar analisis fungsi nilai kriteria majemuk. Tahapan umpan balik untuk mengkonfirmasi kembali data dan hasil analisa secara komunikatif dan tertulis kepada partisipan untuk mendapat masukan jika masih diperlukan perbaikan. Tahapan terakhir yaitu desain sistem penilaian kinerja agroindustri Kebun Bantaran mengacu pada model IDPMS (Ghalayini, et al., 1997).

\section{HASIL DAN PEMBAHASAN}

Kinerja perusahaan adalah ukuran tingkat keberhasilan manajemen dalam mengelola sumberdaya keuangan perusahaan, terutama pada pengelolaan investasi sebagai upaya untuk menciptakan nilai bagi pemegang saham (Elizabeth, 2000). Artinya kinerja perusahaan merupakan indikator tingkatan prestasi yang dapat dicapai dan mencerminkan keberhasilan manajer/pengusaha. Sedangkan menurut Gibson (1998) kinerja merupakan hasil yang dicapai dari perilaku anggota organisasi.

Sistem penilaian kinerja agroindustri teh diformulasikan berdasarkan hasil kajian penerapan sistem penilaian kinerja yang dilaksanakan di agroindustri teh Kebun Bantaran dengan merujuk pada model IDPMS, mengikuti kondisi aktual sistem penilaian kinerja per bagian yang ada di agroindustri teh Kebun Bantaran. Identifikasi parameter dan variabel kunci, dan nilai estimasi parameter menggunakan acuan model PMQ (Dixon et al., 1990). Desain sistem penilaian kinerja agroindustri teh yang diterapkan saat ini memiliki empat tingkat fungsional terdiri dari manajemen perusahaan, manajemen pabrik, lini produksi dan laboratorium pengendalian kualitas (Gambar 3).

Dari Gambar 3 dapat dijelaskan bahwa setiap tingkatan fungsional dihubungkan dengan alur garis yang menggambarkan aliran informasi penilaian kinerja. Tingkat manajemen perusahaan mengevalusi seberapa besar agroindustri teh memberi profit terhadap perusahaan dalam rangka memuaskan pemangku kepentingan dalam hal ini yaitu pemerintah. Sedangkan tingkat manajemen pabrik menerjemahkannya ke dalam seperangkat ukuran kesuksesan bersama yaitu rendemen teh sebagai konsesus bersama ukuran kinerja. Kinerja rendemen teh menjadi tanggung jawab semua bagian yaitu bagian tanaman, bagian teknik dan pengolahan, serta bagian akuntansi dan umum. 
Aulia Brilliantina, Bambang Herry Purnomo, I.B. Suryaningrat. Sistem Penilaian Kinerja Agroindustri Teh Kebun Bantaran PT Perkebunan Nusantara XII

Tingkat manajemen pabrik dikoordinir oleh Manajer Kebun. Peran Manajer Kebun memiliki posisi sentral sebagai mediator antar bagian manajemen pabrik agar saling bersinergi dalam mencapai tujuan kinerja perusahaan berdasarkan ukuran kinerja yang telah disepakati bersama. Ukuran kinerja lini produksimenggambarkan ukuran kesuksesan kinerja tingkat manajemen pabrik. Lab QC bertanggung jawab menyampaikan hasil laporan kinerja mutu teh yang dihasilkan oleh bagian pengolahan.

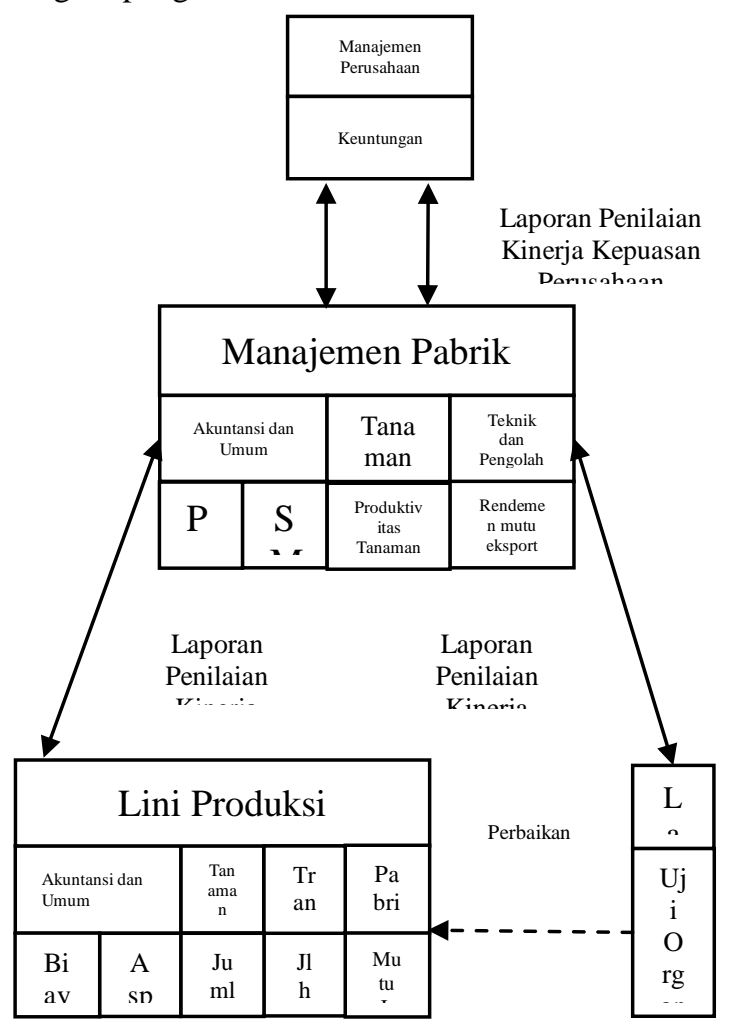

Gambar 3. Sistem Penilaian KinerJa Agroindustri TEH MENGGUNAKANMODELIDPMS

Agroindustri teh menerapkan sistem pengukuran kinerja mengacu pada landasan penilaian kinerja yang di tetapkan oleh PT Perkebunan Nusantara XII. Landasan penilaian kinerja tersebut dijadikan sebagai sistem manajemen kinerja pada agroindustri teh yang bertujuan untuk meningkatkan produktivitas agroindustri teh serta pengembangan individu karyawan. Berdasarkan laporan sistem penilaian kinerja dan hasil PMQ diperoleh beberapa area bagi kesuksesan kinerja agroindustri teh (Tabel. 1).Area kesuksesan agroindustri teh memiliki keterkaitan antara satu dengan lainnya, dimana kepuasan pemangku kepentingan menjadi area kunci utama kesuksesan agroindustri teh (Gambar 4).
Tabel 1. Area Kesuksesan Agroindustri Teh

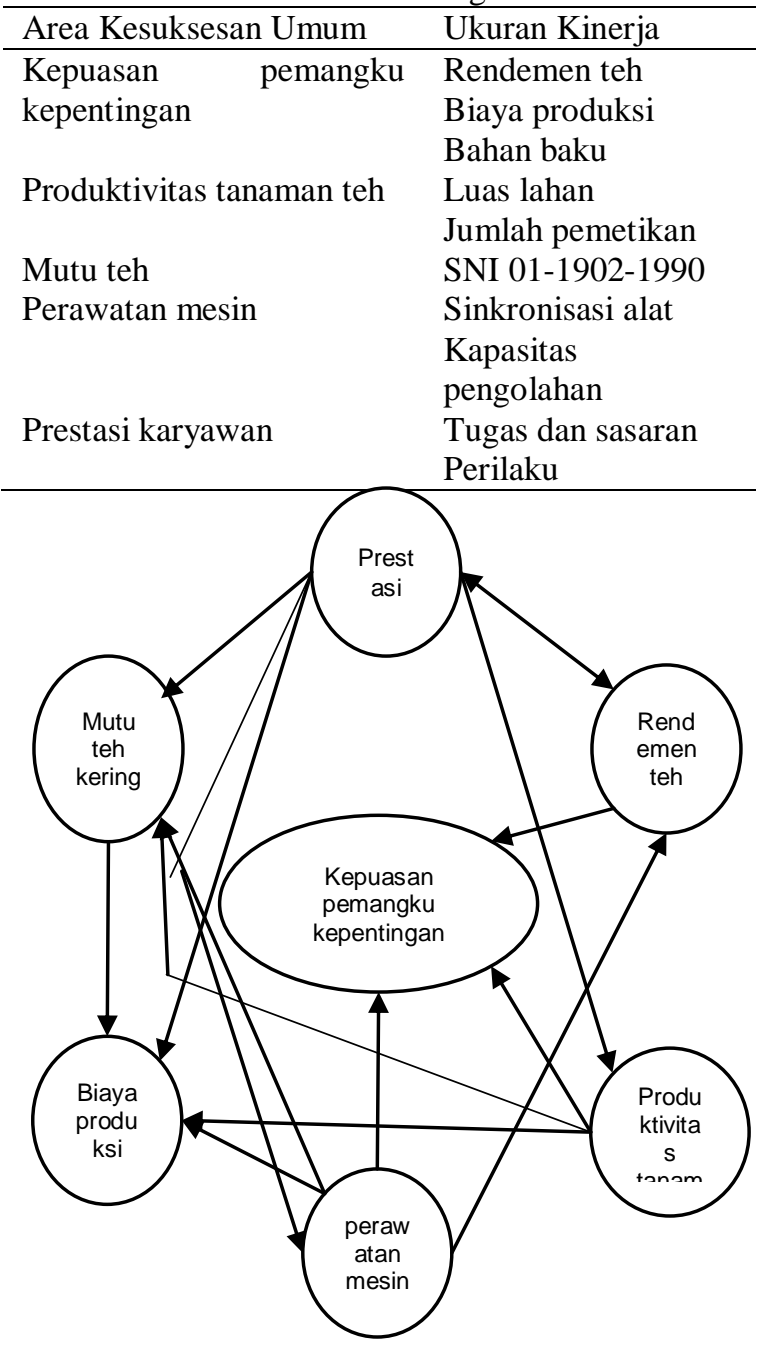

GAMBAR 4. KetERKAitAN AREA KeSUKSESAN AGROINDUSTRI TEH

Area kesuksesan selanjutnya diidentifikasi lebih spesifik seperti kepuasan pemangku kepentingan, rendemen teh, dan bahan baku (Gambar 5-7). Kinerja kepuasan pemangku kepentingan dipengaruhi penilaian kinerja (PK) rendemen teh, jumlah dan mutu bahan baku, serta biaya produksi (Gambar 5). Kinerja rendemen teh menggambarkan total jumlah produksi teh kering yang dihasilkan. PK dari produksi teh kering merupakan jumlah dari mutu I, mutu II, dan mutu lokal yang dihasilkan. Indikator Kinerja (IK) dari mutu sendiri yaitu terdiri dari kenampakan teh kering, air seduhan, serta ampas seduhan. Bagian yang bertanggung jawab penentuan mutu teh yaitu lab QC.

Kinerja bahan baku merupakan jumlah produktivitas tanaman dikalikan luas lahan, serta penambahan pembelian bahan baku dari kebun lain. IKjumlah bahan baku yaitu produktivitas tanaman teh, luas lahan, pembelian, serta 
pengangkutan. Sistem pengangkutan harus benarbenar diperhatikan agar tidak dihasilkan daun yang rusak dan rusak berat, sehingga akan dihasilkan rendemen yang tinggi. Pucuk yang memiliki mutu yang baik akan menghasilkan teh kering dengan kualitas yang baik pula, sebab hampir $60 \%$ mutu teh dipengaruhi oleh kondisi pucuk tehnya.

Sumberdaya manusia pada agroindustri teh memegang peranan yang sangat penting dalam keberhasilan meningkatkan efisiensi nilai indikator kinerja agroindustri teh. Prestasi karyawan pada agroindustri teh ditentukan berdasarkan hasil penilaian kinerja menggunakan perangkat sistem penilaian kinerja. Efisiensi agroindustri pada akhirnya memicu penilaian kinerja biaya produksi menjadi rendah dimana indikator kinerjanya terdiri dari biaya penanaman, teknik dan pengolahan, serta biaya pengeluaran lainnya.

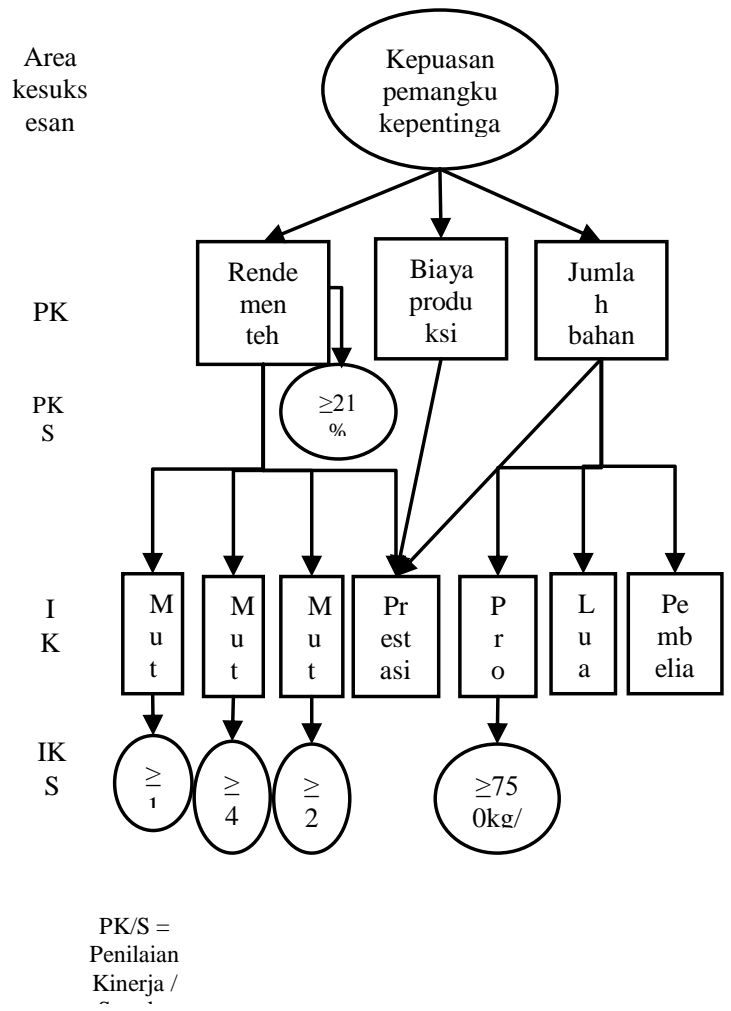

GAMBAR 5. KINERJA KEPUASAN PEMANGKU KEPENTINGAN

Ukuran kesuksesan rendemen teh dipengaruhi oleh PK jumlah mutu I, mutu II, dan mutu lokal yang dihasilkan. Mutu I memiliki IK berupa mutu BPI(Broken Pekoe 1) dengan nilai indikator kinerja standar (IKS) minimal sebesar 2\%, PFI (Pekoe Fanning) minimal sebesar 5\%, PDI (Pekoe Dust 1) minimal sebesar 4\%, dan D1 (Dust 1) minimal sebesar 4\%. Mutu II memiliki IK berupa F (Fanning) dan D2 (Dust 2). Sedangkan yang terakhir yaitu mutu lokal memiliki IK berupa mutu TW dan pluff (gambar 6). Penentuan jenis mutu I, mutu II dan mutu lokal memiliki indikator yang sama, hanya berbeda pada nilai indikator standar. Indikator tersebut yaitu kenampakan teh, air seduhan teh, serta ampas seduhan teh (Rayati, 2009). Untuk kenampakan teh dilihat dari bentuk,ukuran, dan kerataan partikel, warna partikel dan kerataannya, kebersihan dari serat, tulang daun serta benda asing. Untuk air seduhan dinilai dari warna, kepekatan, kejernihan, kecerahanair seduhan, rasa dan bau dari air seduhan. Untuk ampas seduhan dinilai dari warna dan kerataannya. Penentuan jenis mutu ini dilakukan dengan uji sensoris yang bersifat subjektif. Walaupun begitu, uji sensoris sampai saat ini masih merupakan metode utama yang diakui untuk menguji utu teh.

Peningkatan rendemen juga dipengaruhi oleh sinkronisasi alat penggilingan, fermentasi, dan pengeringan. Menurut Susanto (1974), sinkronisasi disini yaitu suatu proses yang kontinyu dan sinkron dari mulai menggiling, fermentasi, dan mengeringkan, menjadi satu lingkaran, sehingga apabila terjadi stagnansi dari salah satu bagian, menjadi sangat mempengaruhi bagian lainnya dan selain itu juga sangat mempengaruhi mutu, serta dapat meningkatkan biaya produksi

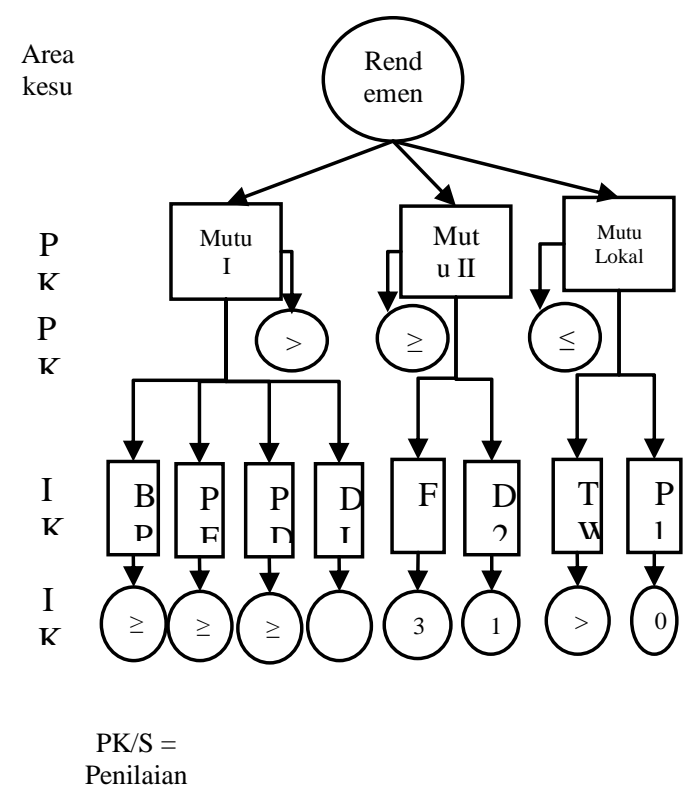

GAMBAR 6. KINERJA RENDEMEN AGROINDUSTRI TEH

Kinerja jumlah bahan baku dinyatakan dengan beberapa PK seperti produktivitas tanaman teh, luas lahan, pembelian, serta pengangkutan (Gambar 7). Nilai produktivitas tanaman teh merupakan jumlah kilogram dari hasil panen per hektar. Nilai produktivitas sendiri dipengaruhi oleh beberapa faktor, yaitu faktor genetik seperti klon dan kandungan senyawa-senyawa kimia dalam 
Aulia Brilliantina, Bambang Herry Purnomo, I.B. Suryaningrat. Sistem Penilaian Kinerja Agroindustri Teh Kebun Bantaran PT Perkebunan Nusantara XII

daun, faktor lingkungan seperti letak ketinggian kebun, faktor kultur teknis seperti pemangkasan, pemupukan, pemetikan, dan sebagainya (Soedradjat, 1986). Menurut Ghani (2002) dalam sistem budidaya teh, pengelolaan pembibitanmerupakan titik kritis yang menentukan proses selanjutnya. Sekali salah dalam menentukan jenis atau klon yang ditanam maka perlu waktu puluhan tahun untuk menggantinya karena umumnya tanaman teh diremajakan setelah berumur 50 tahun. Luas lahan untuk agroindustri teh kebun bantaran sendiri terdapat lahan yang berupa tanaman belum menghasilkan (TBM). TBM merupakan tanaman teh muda dan berumur di bawah dua tahun serta belum diambil produksinya (Tobroni dan Adimulya, 1997). Untuk lahan TBM sendiri agroindustri teh menargetkan hanya sebesar $<5 \%$ dari luas lahan keseluruhan.

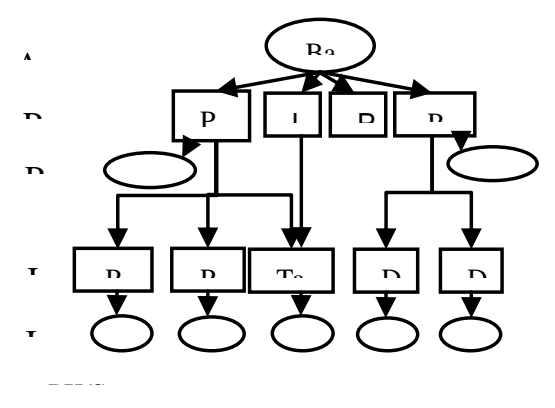

GAMBAR 7.UKURAN KESUKSESAN BAHAN BAKU

Berdasarkan paparan ketiga ukuran kesuksesan kinerja di atas, terlihat keterkaitan yang mencerminkan sebuah sistem PK yang ditetapkan agroindustri teh pada umumnya. Dengan memahami keterkaitan penilaian kinerja tersebut dapat dijadikan landasan bagi pihak manajemen untuk berfokus pada upaya perbaikan yang baik. Misalnya jika manajemen ingin mengambil keputusan meningkatkan investasi biaya pelatihan karyawan, maka manajemen tidak hanya selalu mengukur pengaruhnya terhadap peningkatan kinerja keuangan yang diinginkan sebagai justifikasi tunggal.

Dengan adanya gambaran keterkaitan antara masing-masing ukuran kinerja, manajemen dapat menjustifikasi pengaruh investasi pelatihan karyawan terhadap ukuran kinerja yang diharapkan (Tabel 2). Adanya peningkatan biaya pelatihan dapat meningkatkan kinerja dari rendemen yang menunjukkan adanya peningkatan rendemen teh yang dihasilkan yaitu sebesar $4 \%$. Biaya produksi juga dapat diturunkan sebesar 5\%. Dengan demikian, pemahaman keterkaitan antar ukuran kinerja dapat menjadi alat terbaik dalam pengambilan keputusan perbaikan proses secara komprehensif.
TABEL 2. PENGARUH PENINGKATAN BIAYA PELATIHAN TERHADAP PENINGKATAN KINERJA

\begin{tabular}{|c|c|c|c|c|c|c|c|c|c|}
\hline \multicolumn{2}{|c|}{ Mutu } & \multicolumn{2}{|c|}{$\begin{array}{c}\text { Biaya } \\
\text { produksi }\end{array}$} & \multicolumn{2}{|c|}{$\underset{\mathrm{n}}{\text { Rendeme }}$} & \multicolumn{2}{|c|}{$\begin{array}{l}\text { Produktiv } \\
\text { itas } \\
\text { tanaman }\end{array}$} & \multicolumn{2}{|c|}{$\begin{array}{c}\text { Perawata } \\
\mathrm{n} \text { mesin }\end{array}$} \\
\hline & $\%$ & & $\%$ & & $\%$ & & $\%$ & & $\%$ \\
\hline & $\mathrm{ca}$ & & $\mathrm{ca}$ & & $\mathrm{ca}$ & & $\mathrm{ca}$ & & $\mathrm{ca}$ \\
\hline \multirow[t]{3}{*}{ PK } & $\mathrm{pa}$ & PK & pa & PK & pa & PK & pa & PK & pa \\
\hline & ia & & ia & & ia & & ia & & ia \\
\hline & $\mathrm{n}$ & & $\mathrm{n}$ & & $\mathrm{n}$ & & $\mathrm{n}$ & & $\mathrm{n}$ \\
\hline Pen & 2 & Pen & 5 & Pen & 4 & Pen & 30 & Pen & 60 \\
\hline ing & $\%$ & uru & $\%$ & ing & $\%$ & ing & $\%$ & uru & $\%$ \\
\hline kata & & nan & & kata & & kata & & nan & \\
\hline $\mathrm{n}$ & & bia & & $\mathrm{n}$ & & $\mathrm{n}$ & & ker & \\
\hline mut & & ya & & jum & & jum & & usa & \\
\hline \multirow[t]{4}{*}{ u I } & & $\tan$ & & lah & & lah & & kan & \\
\hline & & am & & teh & & puc & & me & \\
\hline & & an & & keri & & uk & & $\sin$ & \\
\hline & & & & ng & & & & & \\
\hline Pen & 2 & Pen & 5 & & & & & & \\
\hline ing & $\%$ & uru & $\%$ & & & & & & \\
\hline kata & & nan & & & & & & & \\
\hline $\mathrm{n}$ & & bia & & & & & & & \\
\hline mut & & ya & & & & & & & \\
\hline u II & & pab & & & & & & & \\
\hline & & rik & & & & & & & \\
\hline & & asi & & & & & & & \\
\hline Pen & 4 & & & & & & & & \\
\hline uru & $\%$ & & & & & & & & \\
\hline nan & & & & & & & & & \\
\hline mut & & & & & & & & & \\
\hline $\mathrm{u}$ & & & & & & & & & \\
\hline loka & & & & & & & & & \\
\hline 1 & & & & & & & & & \\
\hline
\end{tabular}

\section{KESIMPULAN DAN SARAN KESIMPULAN}

Desain sistem penilaian kinerja agroindustri teh ini mengacu pada model IDPMS yang menyediakan keterkaitan langsung antara ukuran kesuksesan di tingkat manajemen dengan ukuran kinerja di tingkat operasional. Sistem penilaian kinerja memberikan gambaranbahwa kinerja pada agroindustri teh merupakan keterkaitan antar seluruh bagian yang terlibat di kebun (on farm) maupun di pabrik (off farm) yang bersifat komplek dan dinamik. Sistem penilaian kinerja agroindustri yang mengacu pada sistem IDPMS menjadi lebih dinamik dan up to date karena perubahan ukuran kesuksesan di tingkat manajemen langsung direspon di tingkat bawah denganlangsung melakukan perubahan secepatnya. Sistem penilaian kinerja agroindustri teh Kebun Bantaran berfokus pada ukuran kinerja kesuksesan rendemen teh untuk memicu kinerja ukuran keuangan yaitu profit.

\section{SARAN}

Untuk mencapai area kesuksesan yang lebih optimal perlu dilakukan pelatihankepada para mandor secara rutin, agar para mandor lebih memahami tugasnya dikebun. Dalam hal ini perlu 
adanya optimalisasi peran serta dari pimpinan kebundan asisten kepala serta asisten tanaman.

\section{DAFTAR PUSTAKA}

[1] Busi M and US Bititchi. 2006. Collaborative Performance Management ; Present Gap and Future Research. Int'l. J. Productivity and Performance Management, Vol. 55, No. 1, 2006, pp. 7-25

[2] BPS (Badan Pusat Statistik). 2015. Ekspor Teh Menurut Negara Tujuan. www.bps.go.id

[3] Cross, K.F. and Lynch, R.I. The SMART way to define and sustain success. National productivity Review. 1989; vol.8, no. 1, pp. 23-33

[4] Dixon, J et al. 1990. The New Performance Challenge : Measuring Operations for World Class Competition. DowJones Irwin, IL

[5] Elizabeth. (2000). Hubungan Laba Akuntansi dan Arus Kas Terhadap Kinerja Perusahaan. Jurnal RisetAkuntansi Indonesia, 6(2): 76-85

[6] Ghalayini AM, JS Noble dan TJ Crowe. 1997. An Integrated Dynamic Performance Measurement System for Improving Manufacturing Competitiveness. Int'l. J. OfProduction Economics, 48, p. 207-225.

[7] Ghani, M. A. 2002. Buku Pintar Mandor : DasarDasar Budi Daya Teh. Penebar Swadaya. Jakarta. 134 hal.

[8] Gibson et al. (1994). Organisasi. Jilid 1. alih bahasa Agus Dharma. Jakarta: Erlangg

[9] Indonesia Tea Board. 2015. Areal Produksi Teh. www.indonesiateaboard.org

[10] Kaplan RS dan DP Norton. 1996. Balanced Scorecard, Translating Strategi into Action. Terjemahan. Jakarta : Penerbit Erlangga

[11] Nazir M. 1999. Metode Penelitian. Jakarta : Ghalia Indonesia

[12] Peppard and Rowland. 1995. The Essence of Business Process Re-Engineering. Prentice-Hall International

[13] Rayati, D.J dan Widayat, Wahyu. 2009. More Than A Cup Of Tea. Bandung : Pusat Penelitian Teh dan Kina

[14] Soedradjat, Rulan. 1986. Faktor-Faktor Yang Mempengaruhi Mutu Teh Hitam. Bandung : Balai Penelitian Teh dan Kina

[15] Susanto, Carlina. 1974. Tea Processing. Rome : Food And Agriculture Organization of The United Nations

[16] Tobroni, M dan S. Adimulya. 1997. Petunjuk Kultur Teknik Tanaman Teh. Edisi 2. Pusat Penelitian Teh dan Kina. Gambung . 151 hal. 
